\title{
Autonomic Nervous Activity during Hand Immersion in Cold Water in Patients with Vibration-Induced White Finger
}

\author{
Hisataka SAKAKIBARA ${ }^{1 *}$, Jin LUO ${ }^{2}$, San-Kuan ZHU$^{2}$, Mamoru HIRATA ${ }^{3}$, and Mitsuru ABE ${ }^{4}$ \\ ${ }^{1}$ Nagoya University School of Health Sciences, 1-1-20, Daiko-minami, Higashi-ku, Nagoya 461-8673, Japan \\ ${ }^{2}$ Nagoya University School of Medicine, 65 Tsurumai-cho, Showa-ku, Nagoya 466-8550, Japan \\ ${ }^{3}$ National Institute of Industrial Health, 21-1, Nagao 6-chome, Tama-ku, Kawasaki 214-8585, Japan \\ ${ }^{4}$ Oita Kensei Hospital, 1-1-15, Kogaturu, Oita 870-0935, Japan
}

Received July 23, 2001 and accepted March 1, 2002

\begin{abstract}
Autonomic nervous function in response to cold was investigated in 21 patients with vibration-induced white finger (VWF) and 17 healthy controls of similar age, using power spectral analysis of heart rate variability. In a supine position, electrocardiogram and skin temperature of both index fingers were measured during immersion of right hand in cold water at $10^{\circ} \mathrm{C}$ for 10 minutes. Autonomic nervous activity was evaluated from the power of the low-frequency component (LF: 0.02-0.15 Hz), the high-frequency component (HF: 0.15-0.40 Hz) and the ratio of the LF to the HF power (LF/HF ratio). The LF/HF ratio, an index of sympathetic nervous activity, significantly increased during the immersion in the VWF patients, but did not significantly increase in the controls. The $\mathrm{LF} / \mathrm{HF}$ ratio was then significantly greater in the patients than in the controls during the first 12 minutes of the immersion. The HF power related to parasympathetic nervous activity did not change significantly in either group. Finger skin temperature of the immersed right hand was significantly lower in the VWF patients than in the controls during the last five minutes of the immersion and in the recovery period. The present results indicate that sympathetic nervous response to cold is significantly enhanced in VWF patients. The exaggerated sympathetic response to cold in these patients is considered to contribute to the enhanced vasoconstriction of their extremities.
\end{abstract}

Key words: Sympathetic nervous activity, Raynaud's phenomenon, Hand-arm vibration

\section{Introduction}

Prolonged vibration exposure can cause vibration-induced white finger (VWF) among operators of hand-held vibratory tools. The blanching attacks are induced by pathological vasospasm of the finger, usually following exposure of the whole body to cold conditions in winter ${ }^{1)}$. Such enhanced vasospastic response to cold is considered to result from an exaggerated central sympathetic vasoconstrictor reflex and local changes in the digital vessels (e.g., thickening of the

*To whom correspondence should be addressed. muscular wall, endothelial damage, functional receptor changes $)^{2-4)}$. The authors have previously indicated that VWF patients have lower skin temperature in both fingers and toes, and that they are more likely to complain of coldness in the four extremities, as compared with healthy subjects ${ }^{5,6}$. The low skin temperature of the extremities can be linked with their increased sympathetic response to cold ${ }^{7}$.

In recent years, power spectral analysis of heart rate variability has been developed and used as a quantitative and noninvasive means of assessing autonomic nervous function $^{8-11)}$. The method is also used in occupational and environmental health fields ${ }^{12}$. The analysis can provide an 
indicator of sympathetic and parasympathetic nervous functions separately, by dividing the power spectrum of heart rate variability into high-frequency (HF) and low-frequency (LF) components. The former is related to parasympathetic nervous activity, while the ratio of the LF to the HF power is considered as an index of sympathetic nervous activity or sympatho-vagal balance.

Using the power spectral analysis of heart rate variability, the present study aimed to evaluate the autonomic nervous response to cold in VWF patients and to investigate its relationship to their vasospastic characteristics.

\section{Subjects and Methods}

The subjects were 21 male patients with VWF and 17 healthy male volunteers. The patients had experienced VWF within the last year. They were selected from among patients under treatment at a hospital in Oita, Kyushu, Japan. They all had been officially diagnosed with hand-arm vibration syndrome through specific examinations including cold provocation test ${ }^{13)}$. The control volunteers were collected from among healthy residents near the hospital who had no occupational experience of operating vibrating tools. Both subjects were selected from those aged 50-65 years without heart disease, hypertension, cerebrovascular disease, diabetes mellitus, rheumatic disease, liver disease or severe injuries to the upper extremities. All subjects gave informed consent to the study.

In a supine position, the subjects rested quietly for about 30 minutes (rest period), then immersed their right hand up to the wrist in cold water at $10^{\circ} \mathrm{C}$ for 10 minutes (cold water immersion), and thereafter kept their hand out of the water for 10 minutes (recovery period). In the meantime, surface electrocardiogram (ECG) and respiratory wave (nose-tip thermistor) were continuously recorded on a 2-channel Holter ECG recorder (SM-50, Fukuda Denshi Co., Japan). Skin temperature of both index fingers was also automatically measured through an electrode thermometer (HR116, Takara Thermistor Instrument Co., Japan) at an interval of 30 seconds. The room temperature under study ranged within $27 \pm 1^{\circ} \mathrm{C}$.

After the experiment, ECG signals were converted to RR interval signals in a digitized form with a sampling time of $2 \mathrm{~ms}$. Power spectral analysis was then performed with a microcomputer (PC-9801, NEC Co., Japan), using the algorithm of maximum entropy method ${ }^{14}$. The power spectra of RR intervals were divided into the low-frequency component (LF: $0.02-0.15 \mathrm{~Hz}$ ) and the high-frequency component (HF: $0.15-0.40 \mathrm{~Hz}$ ), and the ratio of the LF to
Table 1. Demographic characteristics of subjects (means \pm SD)

\begin{tabular}{lcr}
\hline & $\begin{array}{c}\text { VWF patients } \\
(\mathrm{n}=21)\end{array}$ & \multicolumn{1}{c}{$\begin{array}{c}\text { Controls } \\
(\mathrm{n}=17)\end{array}$} \\
\hline Age (years) & $59.3 \pm 3.7$ & $58.8 \pm 4.6$ \\
Height $(\mathrm{cm})$ & $161.3 \pm 5.0$ & $162.5 \pm 5.4$ \\
Weight $(\mathrm{kg})$ & $59.7 \pm 5.7$ & $61.7 \pm 8.3$ \\
Years operating vibratory tools & $22.5 \pm 5.6$ & \multicolumn{2}{|c}{-} \\
Years of treatment & $3.5 \pm 2.5$ & \multicolumn{2}{|c}{-} \\
Smoking (\%) & $11(52 \%)$ & $8(47 \%)$ \\
Drinking (\%) & $13(62 \%)$ & $13(68 \%)$ \\
\hline
\end{tabular}

the HF component power (LF/HF ratio) was calculated.

In the rest period, RR interval data were analyzed for 128 seconds, which ended one minute before immersing the hand in cold water. During the immersion, four consecutive series of 128-second RR interval data were analyzed, with the first series starting 30 seconds after the immersion. In the recovery period, the first series began one minute after the end of the immersion, and in total four consecutive series of 128-second RR interval data were analyzed. The respiratory rate per minute was calculated from 128 -second respiratory wave data corresponding to 128 -second RR interval data analyzed.

Statistical comparison between the VWF patients and the controls was made with repeated measures analysis of variance and $t$-test evaluated using the p-value that was multiplied by the number of $t$-tests made. Changes from the initial values in the rest period were statistically analyzed by repeated measures analysis of variance and Dunnet $t$ test.

\section{Results}

As shown in Table 1, the mean age was similar in both groups: 59.3 years (SD 3.7, range 52-65) in the VWF patients and 58.8 years (SD 4.6, range 51-65) in the controls. There were no significant differences in height, weight, and drinking or smoking habits.

Figs. 1, 2 and 3 present the changes of power spectrum of heart rate variability in the cold water immersion. The LF power in both groups significantly changed in the immersion ( $\mathrm{F}=3.67, \mathrm{p}<0.01$, for the VWF patients; $\mathrm{F}=3.00$, $\mathrm{p}<0.01$, for the controls). A significant increase was found at the first spectral analysis (around the first 1-2 minutes) during the immersion in both groups $(\mathrm{p}<0.05)$. The LF power at that moment tended to be greater in the patients, but the difference was not significant. The HF power did not show a significant increment during the immersion in either group. The LF/HF ratio significantly increased in the patients 


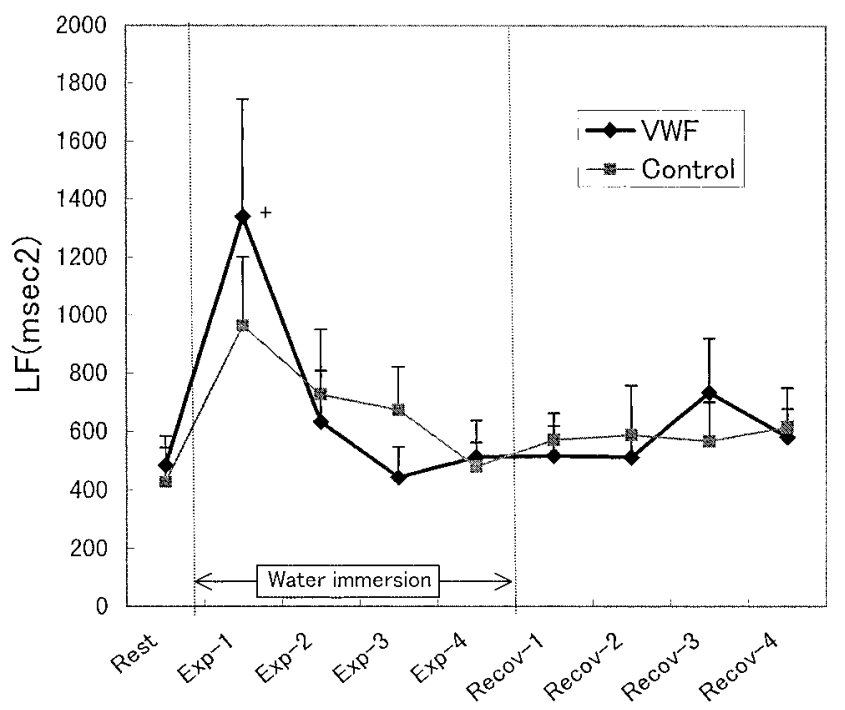

Fig. 1. Changes in LF power during immersion of right hand in cold water at $10^{\circ} \mathrm{C}$ for 10 minutes.

Values are means \pm SE. $+\mathrm{p}<0.05$, statistical difference compared with initial value in the rest period by Dunnet $t$-test.

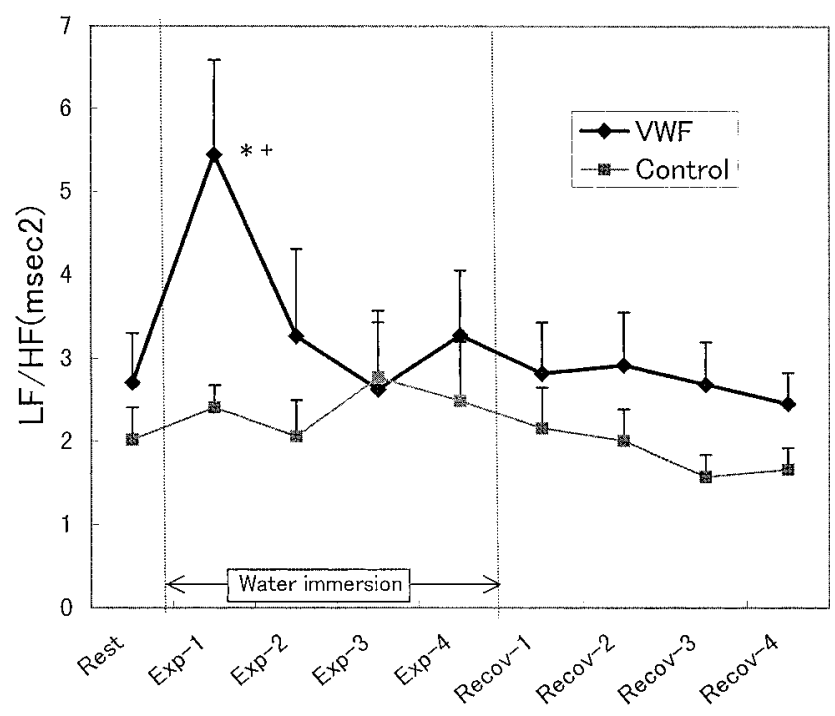

Fig. 3. Changes in LF/HF ratio during immersion of right hand in cold water at $10^{\circ} \mathrm{C}$ for 10 minutes.

Values are means + SE. ${ }^{*} \mathrm{p}<0.05$, statistical difference between VWF patients and controls by $t$-test evaluated as multiple comparison. $+\mathrm{p}<0.05$, statistical difference compared with initial value in the rest period by Dunnet $t$-test.

$(\mathrm{F}=2.48, \mathrm{p}<0.05)$, but did not significantly increase in the controls. The ratio in the patients significantly rose at the first spectral analysis during the immersion $(\mathrm{p}<0.05)$, and it was then significantly greater than in the controls $(p<0.05)$.

The mean values of RR intervals in the rest period were

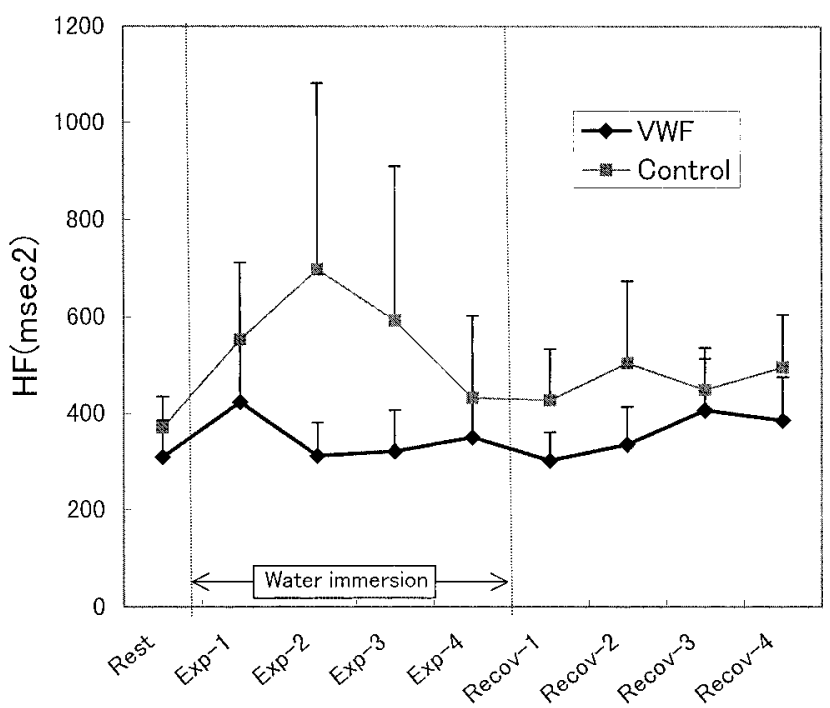

Fig. 2. Changes in HF power during immersion of right hand in cold water at $10^{\circ} \mathrm{C}$ for 10 minutes.

Values are means $\pm \mathrm{SE}$.

Table 2. Changes of RR interval (ms) during immersion of right hand in cold water at $10^{\circ} \mathrm{C}$ for 10 minutes

\begin{tabular}{|c|c|c|c|}
\hline & & $\begin{array}{l}\text { VWF patients } \\
\qquad(\mathrm{n}=21)\end{array}$ & $\begin{array}{l}\text { Controls } \\
(n=17)\end{array}$ \\
\hline \multicolumn{2}{|l|}{ Rest } & $1044 \pm 30$ & $929 \pm 19$ \\
\hline \multicolumn{2}{|c|}{ Standard deviation (ms) } & $35 \pm 3$ & $38 \pm 4$ \\
\hline \multicolumn{2}{|c|}{ Coefficient of variation $(\%)$} & $3.3 \pm 0.3$ & $4.2 \pm 0.5$ \\
\hline \multicolumn{2}{|c|}{ Cold water immersion - 1} & $1004 \pm 30 * *$ & $891 \pm 23 * *$ \\
\hline & -2 & $1002 \pm 30 * *$ & $912 \pm 24$ \\
\hline & -3 & $1020 \pm 32$ & $919 \pm 23$ \\
\hline & -4 & $1036 \pm 30$ & $916 \pm 22$ \\
\hline \multirow[t]{4}{*}{ Recovery } & -1 & $1060 \pm 31$ & $944 \pm 21$ \\
\hline & -2 & $1076 \pm 31^{*}$ & $948 \pm 20$ \\
\hline & -3 & $1077 \pm 30^{*}$ & $954 \pm 19$ \\
\hline & -4 & $1088 \pm 31 * *$ & $957 \pm 19$ \\
\hline
\end{tabular}

Values are means \pm SE. ${ }^{*} \mathrm{p}<0.05, * * \mathrm{p}<0.01$ statistical comparison with initial value at rest by Dunnet $t$-test.

significantly larger in the VWF patients than in the controls $(\mathrm{p}<0.01$, Table 2$)$. The coefficient of variation $(\mathrm{CV})$ tended to be smaller in the patients, but there was no significant difference between them. During the cold water immersion, $\mathrm{RR}$ intervals became significantly shorter (i.e., heart rate increased) in both groups $(\mathrm{F}=16.5, \mathrm{p}<0.01$, for the VWF patients; $F=6.10, \mathrm{p}<0.01$, for the controls). Meanwhile, respiratory rates (around 15 or 16 per minute) were not significantly different between the two groups.

Figs. 4 and 5 show the changes in skin temperature of 


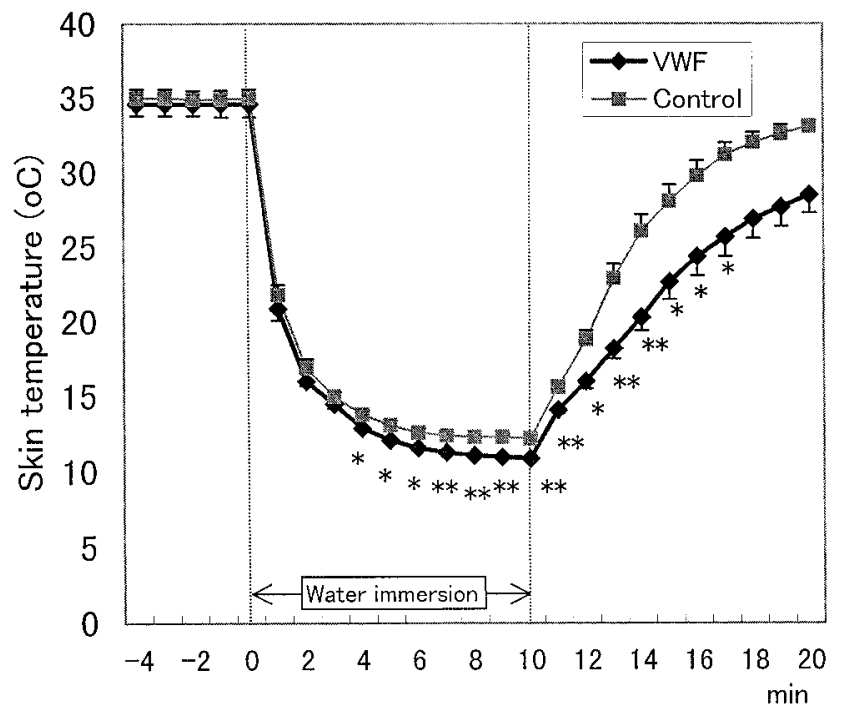

Fig. 4. Changes in skin temperature of right index finger during immersion of right hand in cold water at $10^{\circ} \mathrm{C}$ for 10 minutes. Values are means + SE. ${ }^{*} \mathrm{p}<0.05,{ }^{*} * \mathrm{p}<0.01$, statistical difference between VWF patients and controls by $t$-test evaluated as multiple comparison.

index fingers in the cold water immersion. Skin temperature of both index fingers in the rest period was not significantly different between the two groups, though it tended to be lower in the VWF patients. But skin temperature of the right finger in the cold water immersion was significantly lower in the VWF patients than in the controls $(\mathrm{F}=19.33$, $\mathrm{p}<0.01)$. Significant differences between them were encountered during the last five minutes of the immersion and in the recovery period $(\mathrm{p}<0.05$ or 0.01$)$. Skin temperature of the left finger also significantly decreased during the immersion $(\mathrm{F}=4.23, \mathrm{p}<0.01)$, and it was significantly lower in the patients than in the controls $(\mathrm{F}=5.11, \mathrm{p}<0.05)$.

\section{Discussion}

In earlier studies, autonomic nervous function was assessed using the $\mathrm{CV}$ of heart rate variability at rest, which is known to reflect cardiac vagal tone or cardiac parasympathetic nervous activity ${ }^{15}$. These investigations showed that the $\mathrm{CV}$ in VWF patients is significantly smaller than that in healthy controls, and that sympathetic nervous activity is dominant in VWF patients as a result of suppressed parasympathetic nervous activity ${ }^{16-20)}$. The present study also observed that the CV tended to be smaller in the VWF patients than in the controls, though the difference was not significant. The main findings of these studies are that parasympathetic nervous activity in VWF patients is suppressed at rest. However, they do not show the autonomic

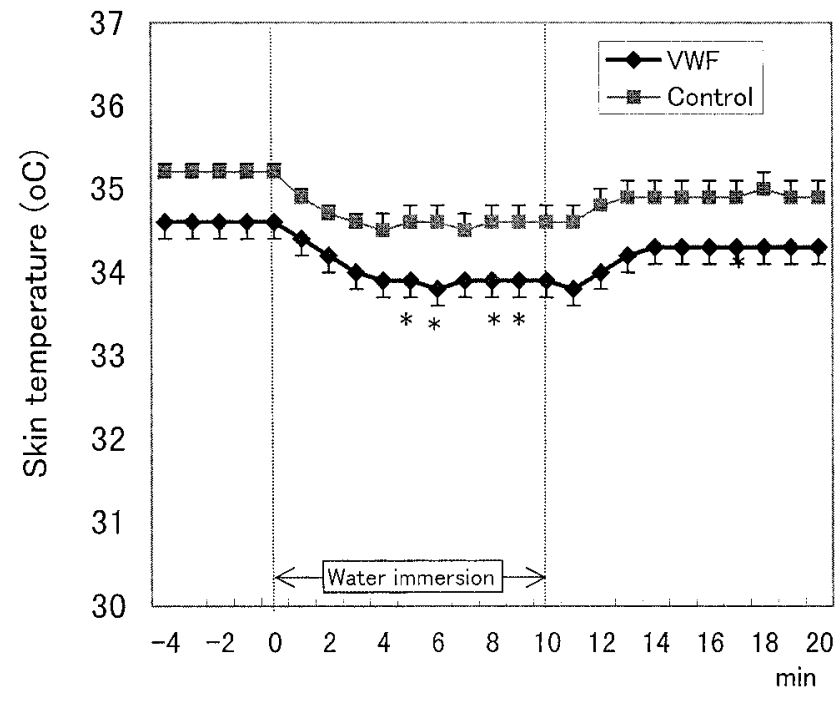

Fig. 5. Changes in skin temperature of left index finger during immersion of right hand in cold water at $100 \mathrm{C}$ for 10 minutes. Values are means + SE. ${ }^{*} \mathrm{p}<0.05$, statistical difference between VWF patients and controls by t-test evaluated as multiple comparison.

nervous response to cold conditions.

The present study evaluated autonomic nervous function during cold water immersion using power spectral analysis of heart rate variability. In the analysis, the LF/HF ratio, an index of sympathetic nervous activity, significantly increased in the VWF patients during the first few minutes of immersion. The ratio was then significantly greater in the VWF patients than in the controls. Meanwhile, the HF power related to parasympathetic nervous activity did not change significantly. The present findings have shown that in cold water immersion of the hand sympathetic nervous activity is significantly increased in VWF patients, while parasympathetic nervous activity is not changed significantly.

Sympathetic nervous activity in the VWF patients during the hand immersion in cold water at $10^{\circ} \mathrm{C}$ for 10 minutes was markedly increased in the first few minutes of the immersion and then decreased to about its initial value. This is consistent with the previous findings. Shiomi et al. reported that systolic blood pressure in chain-saw operators was significantly increased at the second minute in $10^{\circ} \mathrm{C}$ water immersion $^{21)}$. Nakamoto also indicated that the level of plasma norepinephrine in healthy persons was increased only for the first few minutes of the immersion in $10^{\circ} \mathrm{C}$ water ${ }^{22}$. Thus, in the case of the hand immersion in $10^{\circ} \mathrm{C}$ water, sympathetic nervous activity in VWF patients is enhanced in the first few minutes of the immersion.

In the rest period, finger skin temperature of both hands did not significantly differ between the VWF patients and 
the controls, though it tended to be lower in the patients. But during the cold water immersion skin temperature of the right finger dropped rapidly and thereafter, particularly during the last five minutes of the immersion, it was significantly lower in the patients than in the controls. During the immersion, the skin temperature of the left finger also decreased so as to become significantly lower in the VWF patients. It is, hence, considered that hand cooling causes increased sympathetic nervous activity in VWF patients which contributes to their lower skin temperature during the immersion.

Nakamoto reported that whole-body cooling produced a constant increase in plasma norepinephrine during cold exposure, whereas hand cooling increased plasma norepinephrine temporarily for the first few minutes of the cooling ${ }^{22}$. This finding indicates that sympathetic nervous activity in VWF patients is likely to be continuously enhanced by whole body cooling. This may be a reason why blanching attacks in VWF patients are frequently induced by wholebody cooling in winter.

The exaggerated sympathetic activity in response to cold among VWF patients has been shown by examining finger systolic blood pressure with and without local anesthesia of the digital nerves ${ }^{23)}$, the cardiac systolic time interval ${ }^{24)}$, and the level of plasma norepinephrine ${ }^{22,25)}$ or skin sympathetic nervous activity ${ }^{26}$. The present study has also shown that sympathetic nervous response to cold is significantly enhanced in VWF patients compared with healthy controls. The exaggerated sympathetic response to cold in the patients is considered to contribute to the enhanced vasoconstriction of their extremities that may lead to the blanching attacks.

\section{References}

1) Pelmear PL (1998) Clinical picture (vascular, neurological, and musculoskeletal). In: Hand-arm vibration, A comprehensive guide for occupational health professionals, 2nd ed. eds. by Pelmear PL, Wasserman DE, 27-43, OEM Press, Massachusetts.

2) Gemne G (1994) Pathophysiology of white fingers in workers using hand-held vibrating tools. Nagoya J Med Sci 75 (suppl), 87-97.

3) Bovenzi M (1998) Hand-transmitted vibration. In: Encyclopedia of Occupational Health and Safety, 4th ed. eds. by Stellman JM, et al., 507-50.13, International Labour Office, Geneva.

4) Sakakibara H (1998) Pathophysiology and pathogenesis of circulatory, neurological, and musculoskeletal disturbances in hand-arm vibration syndrome. In: Handarm vibration, A comprehensive guide for occupational health professionals, 2nd ed. eds. by Pelmear PL, Wasserman DE, 45-72, OEM Press, Massachusetts.

5) Sakakibara H, Akamatsu Y, Miyao M, Kondo T, Furuta M, Yamada S, Harada N, Miyake S, Hosokawa M (1988) Correlation between vibration-induced white finger and symptoms of upper and lower extremities in vibration syndrome. Int Arch Occup Environ Health 60, 31-9.

6) Sakakibara H, Hashiguchi T, Furuta M, Kondo T, Miyao M, Yamada S (1991) Circulatory disturbances of the foot in vibration syndrome. Int Arch Occup Environ Health 63, 145-8.

7) Sakakibara H, Yamada S (1995) Vibration syndrome and autonomic nervous system. Centr Eur J Public Health 3 (Suppl), 11-4.

8) Akselrod S, Gordon D, Ubel FA, Shanon DC, Barger AC, Cohen RJ (1981) Power spectrum analysis of heart rate fluctuation: A quantitative probe of beat-to-beat cardiovascular control. Science 213, 220-3.

9) Akselrod S, Gordon D, Madwed JB, Snidman NC, Shannon DC, Cohen RJ (1985) Hemodynamic regulation: investigation by spectral analysis. Am J Physiol 249, H867-75.

10) Pagani M, Lombardi F, Guzzetti S, Rioldi O, Furlan R, Pizzinelli P, Sandrone G, Malfatto G, Dell'Orto S, Piccaluga E, Turiel M, Basseli G, Cerutti S, Malliani A (1986) Power spectral analysis of heart rate and arterial pressure variabilities as a marker of sympathovagal interaction in man and conscious dog. Circ Res 59, 178-93.

11) Pomeranz B, Macaulay RJB, Caudill MA, Kutz I, Adam D, Gordon D, Kilborn KM, Barger AC, Shannon DC, Cohen RJ, Benson H (1985) Assessment of autonomic function in humans by heart rate spectral analysis. Am J Physiol 248, H151-3.

12) Murata K, Araki S (1996) Assessment of autonomic neurotoxicity in occupational and environmental health as determined by ECG R-R interval variability: a review. Am J Ind Med 30, 155-63.

13) Labour Standards Bureau, Japanese Ministry of Labour (1977) Criteria for recognition as vibration hazards. Jpn Med J 2774, 95-7 (in Japanese).

14) Ohtomo N, Terachi S, Tanaka Y, Tokiwano K, Kaneko N (1994) New method of time series analysis and its application to Wolt's sunspot number data. Jpn J Appl Phys 33, 2821-31.

15) Wheeler T, Watkins PJ (1973) Cardiac denervation in diabetes. Br Med J 8, 584-6. 
16) Kobayashi F, Watanabe $T$, Sumi $K$, Maeda $K$, Nakagawa T, Sakakibara H, Miyao M, Yamada S (1987) Evaluation of autonomic nervous activity in patients with vibration disease using electrocardiographic R-R interval variations. Ind Health 25, 83-7.

17) Heinonen E, Färkkilä M, Forsström J, Antila K, Jalonen J, Korhonen O, Pyykkö I (1987) Autonomic neuropathy and vibration exposure in forestry workers. Br J Ind Med 44, 412-6.

18) Harada N, Kondo H, Kimura K (1990) Assessment of autonomic nervous function in patients with vibration syndrome using heart rate variation and plasma cyclic nucleotides. Br J Ind Med 47, 263-8.

19) Murata K, Araki S, Maeda K (1991) Autonomic and central peripheral nervous system dysfunction in workers exposed to hand-arm vibration: A study of R$\mathrm{R}$ interval variability and distribution of nerve conduction velocities. Int Arch Occup Environ Health 63, 205-11.

20) Virokannas H, Tolonen U (1995) Responses of workers exposed to vibration in autonomic nervous function tests. Int Arch Occup Environ Health 67, 201-5.
21) Shiomi $S$, Miyashita $K$, Kasamatsu $T$, Itoh N, Iwata $H$ (1980) A study on the peripheral circulatory function and on the cold pressor response in chain saw operators. Sangyo Igaku 22, 163-8 (in Japanese).

22) Nakamoto M (1990) Responses of sympathetic nerve system to cold exposure in vibration syndrome patients and age-matched healthy controls. Int Arch Occup Environ Health 62, 177-81.

23) Olsen N, Fjeldborg P, Brochner-Mortensen J (1985) Sympathetic and local vasoconstrictor response to cold in vibration induced white finger. Br J Ind Med 42, 272-5.

24) Bovenzi M (1989) Cardiovascular responses to autonomic stimuli in workers with vibration-induced white finger. Eur J Appl Physiol 59, 199-208.

25) Harada N (1994) Autonomic nervous function of handarm vibration syndrome patients. Nagoya J Med Sci 57 (Suppl), 77-85.

26) Ishida G, Nasu Y. Nakashima K, Sato T, Takahashi $K$ (1992) Sympathetic nerve activity in the skin in relation to vibration-induced white finger. Scand J Work Environ Health 18, 124-7. 